\title{
Niemann-Pick C1 protects against atherosclerosis in mice via regulation of macrophage intracellular cholesterol trafficking
}

\author{
Jessie R. Zhang, ${ }^{1}$ Trey Coleman,1 S. Joshua Langmade,1 David E. Scherrer, ${ }^{1}$ \\ Lindsay Lane, ${ }^{1}$ M. Hunter Lanier, ${ }^{1}$ Chu Feng, ${ }^{1}$ Mark S. Sands, ${ }^{1,2}$ Jean E. Schaffer, ${ }^{1,3}$ \\ Clay F. Semenkovich, ${ }^{1,4}$ and Daniel S. Ory'1,4
}

1Department of Medicine, 2Department of Genetics, ${ }^{3}$ Department of Molecular Biology and Pharmacology, and 4Department of Cell Biology and Physiology, Washington University School of Medicine, St. Louis, Missouri, USA.

\begin{abstract}
Niemann-Pick C1 (NPC1) is a key participant in cellular cholesterol trafficking. Loss of NPC1 function leads to defective suppression of SREBP-dependent gene expression and failure to appropriately activate liver $\mathrm{X}$ receptor-mediated (LXR-mediated) pathways, ultimately resulting in intracellular cholesterol accumulation. To determine whether NPC1 contributes to regulation of macrophage sterol homeostasis in vivo, we examined the effect of NPC1 deletion in BM-derived cells on atherosclerotic lesion development in the $\mathrm{Ldlr}^{-/-}$mouse

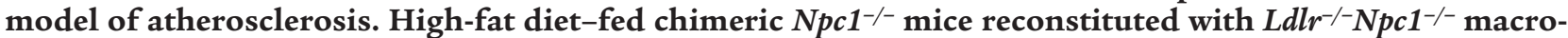
phages exhibited accelerated atherosclerosis despite lower serum cholesterol compared with mice reconstituted with wild-type macrophages. The discordance between the low serum lipoprotein levels and the presence of aortic atherosclerosis suggested that intrinsic alterations in macrophage sterol metabolism in the chimeric $\mathrm{Npc1}^{-/-}$mice played a greater role in atherosclerotic lesion formation than did serum lipoprotein levels. Macrophages from chimeric $\mathrm{Npc1}^{-/-}$mice showed decreased synthesis of 27-hydroxycholesterol (27-HC), an endogenous LXR ligand; decreased expression of LXR-regulated cholesterol transporters; and impaired cholesterol efflux. Lower 27-HC levels were associated with elevated cholesterol oxidation products in macrophages and plasma of chimeric $\mathrm{Npc}^{-/-}$mice and with increased oxidative stress. Our results demonstrate that NPC1 serves an atheroprotective role in mice through regulation of LXR-dependent cholesterol efflux and mitigation of cholesterol-induced oxidative stress in macrophages.
\end{abstract}

\section{Introduction}

Macrophages regulate tissue lipid homeostasis through the uptake and catabolism of atherogenic plasma lipoproteins (1). Macrophages express scavenger receptor A and CD36, which bind and internalize modified lipoproteins, such as oxidized LDL. Upon internalization, lipoprotein-derived cholesterol is delivered to a late endosomal organelle, where cholesterol esters are hydrolyzed to free cholesterol. Delivery of free cholesterol from the endocytic pathway to the plasma membrane and ER requires the coordinated actions of the late endosomal Niemann-Pick C1 (NPC1) and lysosomal NPC2 proteins (2). Delivery of cholesterol to the ER rapidly stimulates esterification and accumulation of cholesterol ester in cytoplasmic droplets. Because the scavenger receptors, in contrast to the LDL receptor (LDLR), are not controlled by a sterol-regulated negative feedback loop, macrophages accumulate massive quantities of lipoprotein-derived lipids.

Nonstandard abbreviations used: AcLDL, acetylated LDL; BMT, BM transplant; GC/MS, gas chromatography/mass spectrometry; HC, hydroxycholesterol; $\mathrm{H}_{2}$ DCFDA, 6-carboxy-2', $7^{\prime}$-dichlorodihydrofluorescein diacetate; LDLR, LDL receptor; LXR, liver X receptor; NPC, Niemann-Pick C; TG, triglyceride.

Conflict of interest: D.S. Ory and C.F. Semenkovich have received lecture honoraria from Merck. C.F. Semenkovich has served as a consultant for Astra-Zeneca, Pfizer, Bristol-Myers Squibb, and CV Therapeutics and is a founder of Meta Therapeutics. Citation for this article: J. Clin. Invest. 118:2281-2290 (2008). doi:10.1172/JCI32561.
To prevent cytotoxicity caused by accumulation of excess cholesterol in macrophages, liver $\mathrm{X}$ receptors (LXRs), together with other members of the nuclear receptor superfamily, contribute to cellular cholesterol homeostasis by regulating genes that contribute to the storage, transport, and catabolism of sterols and their metabolites (1). LXRs respond to elevated cholesterol levels via transactivation of genes involved in sterol transport, cholesterol efflux and HDL metabolism, and sterol catabolism (3). Recent studies have shown that certain oxysterols, such as 27-hydroxycholesterol (27-HC), are specific ligands for the LXRs (4). 27-HC is enzymatically produced in macrophages in response to cholesterol loading and has been proposed to be an important physiological LXR ligand $(5,6)$. Indeed, fibroblasts from patients with cerebrotendinous xanthomatosis (CTX), a disorder caused by deficiency in sterol 27-hydroxylase and characterized by absence of $27-\mathrm{HC}$, exhibit altered sterol regulatory responses (7). CTX is also associated with premature atherosclerosis, although the precise contribution of reduced $27-\mathrm{HC}$ levels to the atherosclerotic phenotype is unclear because the deficiency in 27-hydroxylation also perturbs bile acid synthesis and affects multiple metabolic nuclear receptor (e.g., LXR, farnesoid X receptor, and pregnane $X$ receptor) signaling pathways.

Insight into the mechanisms underlying regulation of cellular cholesterol homeostasis has come from study of the NPC1 gene. Fibroblasts from NPC patients exhibit markedly impaired rates of esterification of LDL-cholesterol $(8,9)$ and mobilization of newly 
A
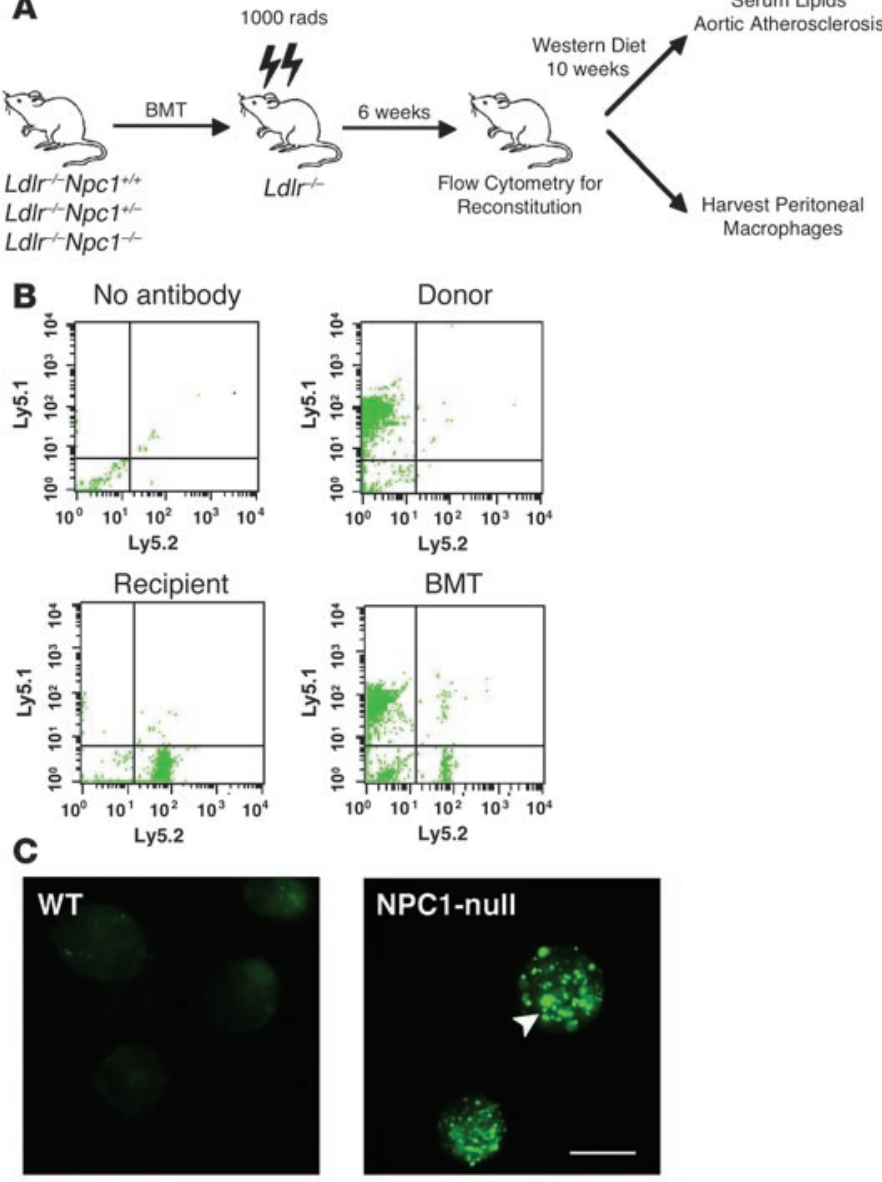

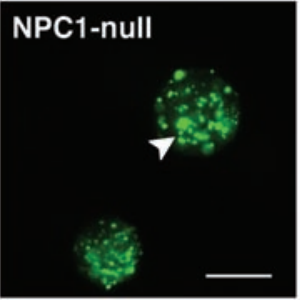

hydrolyzed LDL-cholesterol to the plasma membrane (10-12). As a consequence of these trafficking defects, NPC mutant fibroblasts demonstrate lysosomal sequestration of LDL-cholesterol, delayed downregulation of the LDLR, and de novo cholesterol biosynthesis $(13,14)$. In NPC1-deficient cells, expression of the ABCA1 sterol transporter is reduced, resulting in decreased cholesterol efflux $(15,16)$. Recent studies have shown that the sterol homeostatic defects in NPC disease are caused by failure of lipoprotein cholesterol both to suppress SREBP-dependent gene expression and to promote LXR-mediated responses and are associated with impaired LDL-cholesterol-stimulated production of $25-\mathrm{HC}$ and $27-\mathrm{HC}(17,18)$. Based on these findings, we previously proposed that NPC proteins normally regulate cholesterol homeostasis by channeling excess LDL-cholesterol to intracellular sites of oxysterol synthesis, such as the mitochondrial sterol 27-hydroxylase (CYP27A1), resulting in the generation of LDLcholesterol-derived oxysterols (2).

To test whether NPC1-mediated cholesterol trafficking contributes to regulation of macrophage sterol homeostasis in the vessel wall and modulates susceptibility to atherosclerosis, we examined the effect of Npc1 deletion in BM-derived cells of chimeric mice on atherosclerotic lesion development. We showed that macrophage expression of NPC1 was critical for generation of an endogenous oxysterol LXR ligand and that NPC1 served an atheroprotective role through regulation of LXR-dependent cholesterol efflux and mitigation of cholesterol-induced oxidative stress.

\section{Figure 1}

Analysis of BM reconstitution of $L d l r^{-1-}$ mice after BMT from $L d l r^{-1-}$

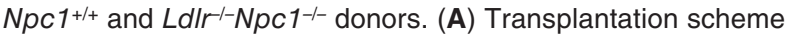
for generation of $L d l r^{-1-}$ mice with BM-derived cells deficient in Npc1. (B) At 6 weeks after BMT, peripheral blood was obtained from recipients, and cells were stained with anti-CD45.1 and antiCD45.2 to identify Ly5.1- and Ly5.2-positive cells by flow cytometry. Data represent $10^{4}$ cells from each mouse. (C) Cholesterol staining of peritoneal macrophages harvested from high-fat fed $\mathrm{M} \phi N p c 1^{+/+}$and $\mathrm{M} \phi N p c 1^{-/-}$chimeric mice. Arrowhead denotes cholesterol-laden lysosomes. Scale bar: $10 \mu \mathrm{M}$.

\section{Results}

Generation of mice with deletion of Npc1 in BM-derived cells. We generated mice with deletion of Npc1 in BM-derived cells using the BM transplant (BMT) strategy shown in Figure 1A. $\mathrm{Npc1}^{+/-}$mice (19) were first backcrossed 8 generations into $\mathrm{Ldlr}^{-/}$mice, a genetically modified mouse line with increased susceptibility to atherosclerotic lesion development on a high-fat diet (20). The $L d l r^{-/} N p c 1^{+/-}$mice were intercrossed with a congenic strain that harbors the Ly5.1 polymorphism to monitor reconstitution after BMT (21). In the transplanted mice, the mean reconstitution efficiency was $91.6 \%$ at 6 weeks $(n=122)$, demonstrating that the hematopoietic lineages were predominantly derived from the donor BM in the chimeric mice (Figure 1B). Repopulation with donor-derived macrophages was confirmed in peritoneal macrophages harvested from chimeric mice reconstituted with $\mathrm{Ldlr}^{-/} \mathrm{Npc1}^{-/-}$macrophages $\left(\mathrm{M} \phi N p c 1^{-/}\right)$by staining for lysosomal accumulation of free cholesterol (Figure 1C), the hallmark of the NPC1 mutant phenotype (14).

Deletion of Npc1 in BM-derived cells alters serum lipoprotein levels. To determine the effect of loss of NPC1 expression on atherosclerotic lesion development, transplanted mice were maintained on a high-fat diet $(0.15 \%$ cholesterol and $42 \%$ fat $)$, which has previously been shown to promote lesion formation in Ldl $r^{\prime-}$ mice (22), and euthanized after 10 weeks. Serum lipid levels were measured after $0,3,6$, and 10 weeks of high-fat diet feeding, revealing significantly lower cholesterol and triglyceride (TG) levels at 6 and 10 weeks in the chimeric $\mathrm{M} \phi N p c 1^{-1-}$ mice compared

\section{Table 1}

Lipoprotein analysis of pooled plasma

\begin{tabular}{|c|c|c|}
\hline & $\mathrm{M}_{\phi} \mathrm{Npc1}^{+/+}$ & $\mathbf{M}_{\phi} \mathrm{Npc1}^{-/-}$ \\
\hline \multicolumn{3}{|c|}{ Cholesterol (mg/dl) } \\
\hline Total & $1,571 \pm 28$ & $961 \pm 29^{A}$ \\
\hline VLDL & $854 \pm 46$ & $486 \pm 33^{A}$ \\
\hline LDL & $554 \pm 32$ & $362 \pm 14 \mathrm{~A}$ \\
\hline $\mathrm{HDL}$ & $119 \pm 1.0$ & $91 \pm 1.7^{\mathrm{A}}$ \\
\hline \multicolumn{3}{|c|}{ TGs (mg/dl) } \\
\hline Total & $256 \pm 16$ & $103 \pm 4.6^{A}$ \\
\hline VLDL & $145 \pm 3.2$ & $56.8 \pm 0.93^{\mathrm{A}}$ \\
\hline LDL & $51 \pm 3.8$ & $23.8 \pm 1.5^{\mathrm{A}}$ \\
\hline HDL & $10.0 \pm 0.47$ & $4.58 \pm 0.57^{\mathrm{A}}$ \\
\hline
\end{tabular}

$\mathrm{M} \phi N p c 1^{+/+}$and $\mathrm{M} \phi N p c 1^{-/-}$mice were fed high-fat diet for 10 weeks. Sera from 5-6 animals per genotype were pooled and separated by FPLC, and individual fractions were assayed for cholesterol and TG content. Data are mean \pm SEM of triplicate determinations for each genotype. ${ }^{\mathrm{A} P} \leq 0.005$ versus $\mathrm{M} \phi N p c 1^{+/+}$. 


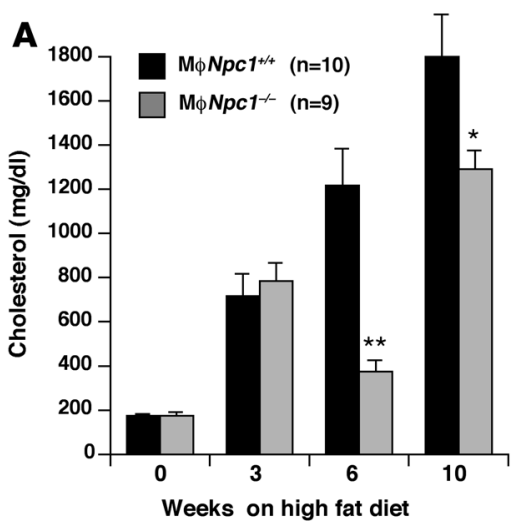

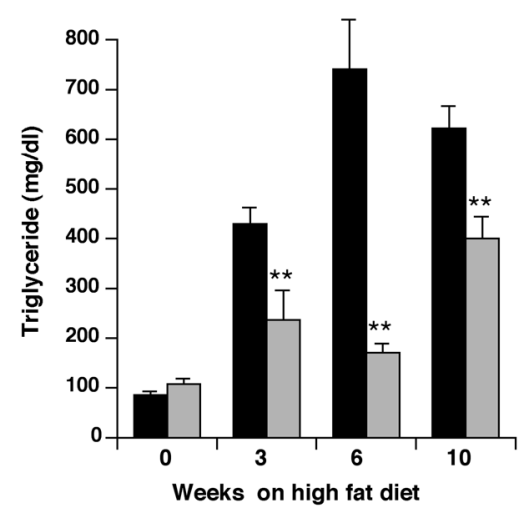

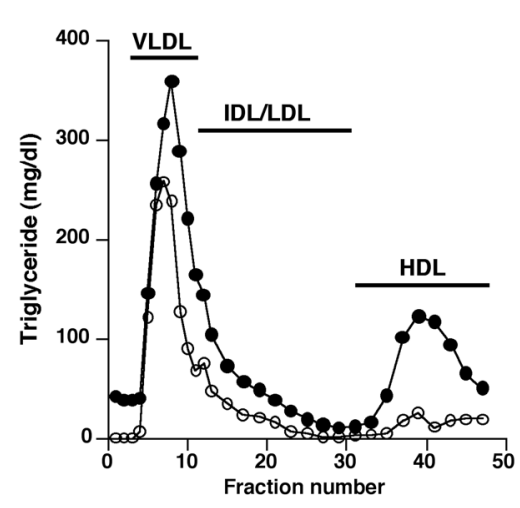

\section{Figure 2}

Serum lipoprotein cholesterol and TG levels in $\mathrm{M} \phi N p c 1^{+/+}$and $\mathrm{M} \phi N p c 1^{-/-}$mice fed an atherogenic diet. (A) Quantitative lipoprotein analysis of serum lipoproteins. Sera from 9-10 animals per genotype fed the high-fat diet for $0,3,6$, and 10 weeks were pooled and analyzed by HPLC. Data are mean \pm SEM. ${ }^{\star} P \leq 0.05,{ }^{\star \star} P \leq 0.005$ versus $\mathrm{M} \phi N p c 1^{+/+}$. (B) FPLC profile of cholesterol and TGs in mice fed the high-fat diet for 10 weeks. Sera from 5-6 animals per genotype were pooled and separated by FPLC, and individual fractions were assayed for cholesterol and TG content. Data represent means of triplicate determinations for each genotype. SEM and statistical analyses are shown in Table 1.

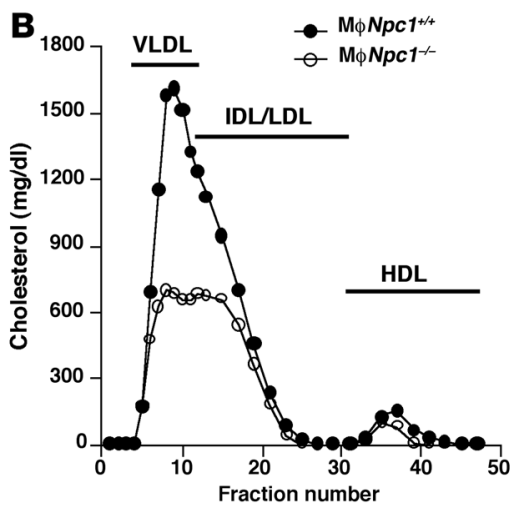

with $\mathrm{M} \phi N p c 1^{+/+}$mice (Figure 2A). Pooled serum lipoprotein profiles obtained from chimeric mice after 10 weeks on the high-fat diet demonstrated significant reductions in both cholesterol and TGs in the VLDL, LDL, and HDL fractions of $\mathrm{M} \phi N p c 1^{-/-}$compared with $\mathrm{M} \phi N p c 1^{+/+}$mice (Figure $2 \mathrm{~B}$ and Table 1). The lower serum lipoprotein levels in the $\mathrm{M} \phi N p \mathrm{N1}^{-/-}$mice were not explained by differences in chow intake (data not shown), body weight (Figure $3 \mathrm{~A})$, fractional cholesterol absorption $\left(\mathrm{M} \phi N p c 1^{++}, 80.1 \% \pm 0.62 \%\right.$; $\mathrm{M} \phi \mathrm{Npc1}^{-1-}, 82.8 \% \pm 2.2 \%$; $\mathrm{P}=\mathrm{NS}$ ), or rate of VLDL synthesis (Figure $3 \mathrm{~B})$. On the other hand, ${ }^{125} \mathrm{I}-\mathrm{VLDL}$ clearance was significantly accelerated in $\mathrm{M} \phi N p c 1^{-/-}$mice compared with $\mathrm{M} \phi N p c 1^{+/+}$mice (Figure 3C) and was accompanied by a hepatic free cholesterol level 1.8-fold that of $\mathrm{M} \phi N p c 1^{+/+}$mice (Figure 3D). Examination of Kupffer cells, BM-derived cells of macrophage lineage located in the lumen of hepatic sinusoids, revealed free cholesterol levels 1.8-fold and cholesterol ester levels 1.9-fold those of $\mathrm{M} \phi N p c 1^{+/+}$mice (Figure 3E), consistent with the NPC phenotype. Because Kupffer cells represent about $10 \%$ of the total hepatic cell population, it is likely that the bulk of the cholesterol is present in hepatocytes and accumulates as a result of increased lipoprotein clearance.

Increased aortic atherosclerosis in high-fat diet-fed $M \phi N p c 1^{-/-}$mice. Despite lower serum lipids, aortic atherosclerosis was accelerated in the $\mathrm{M} \phi \mathrm{NpC1}^{-/-}$mice after 10 weeks on the high-fat diet compared with $\mathrm{M} \phi \mathrm{Npc1}^{+/+}$mice (Figure 4, A and B). There was no evidence for a gene dosage effect with respect to susceptibility to atherosclerosis, because $\mathrm{M} \phi N p c 1^{+/-}$and $\mathrm{M} \phi N p c 1^{+/+}$mice exhibited nearly identical levels of aortic atherosclerosis. Aortic sinus sections in the $\mathrm{M} \phi N p c 1^{-/-}$mice demonstrated markedly increased Oil red O staining for neutral lipid accumulation (Figure 4C). The aortic lesions in both $\mathrm{M} \phi N p c 1^{+/+}$and $\mathrm{M} \phi N p c 1^{-/-}$mice exhibited a high degree of cellularity with extensive macrophage infiltration, in agreement with an earlier report (23), and no changes were observed in the extent of macrophage apoptosis (data not shown). However, $\mathrm{M} \phi N p c 1^{-/-}$mice did not exhibit the profound atherothrombotic phenotype previously observed in the whole-body $\mathrm{Npc1}^{-/-} \mathrm{Apoe^{-/- }}$ mice (23). The discordance between the serum lipoprotein levels and aortic atherosclerosis suggested that intrinsic alterations in macrophage sterol metabolism in the $\mathrm{M} \phi N p c 1^{-/-}$mice likely play a greater role in atherosclerotic lesion formation than do serum lipoprotein levels. Previous studies have shown that NPC1 mutant fibroblasts fail to induce ABCA1 mRNA and protein expression in response to cholesterol loading $(16,24)$ and exhibit impaired ABCA1-mediated cholesterol efflux to apoA-I (15). To investigate whether a defect in activation of the LXR pathway in the $\mathrm{Npc1}^{-/-}$ macrophages contributed to the accelerated atherosclerosis in the $\mathrm{M} \phi N p c 1^{-/-}$mice, we examined $A b c a 1$ and $A b c g 1$ gene expression in peritoneal macrophages harvested from the chimeric mice. We found that lipoprotein-stimulated $A b c a 1$ and $A b c g 1$ mRNA expression was reduced by $49 \%$ and $57 \%$, respectively, in macrophages from $\mathrm{M} \phi \mathrm{Npc1}^{-/-}$mice (Figure 5A). Consistent with these findings, cholesterol efflux to apoA-I and HDL (extracellular acceptors for ABCA1- and ABCG1-mediated cholesterol transport, respectively) was reduced by $55 \%$ and $46 \%$ at 4 hours and by $26 \%$ and $33 \%$ at 24 hours, respectively (Figure 5, B and C). Treatment of $\mathrm{Npc1}^{-/-}$macrophages with T0901317, a synthetic LXR ligand, led to significant increases in cholesterol efflux to both apoA-I and HDL. Indeed, incubation of $\mathrm{Npc1}^{-/-}$macrophages with T0901317 corrected the defect in cholesterol efflux to apoA-I (WT, $19.6 \% \pm 0.94 \% ; \mathrm{Np}^{-/-}$ plus T0901317, 20.8\% $\pm 0.17 \% ; P=N S)$, suggesting that activation with the synthetic ligand is able to bypass, at least in part, 

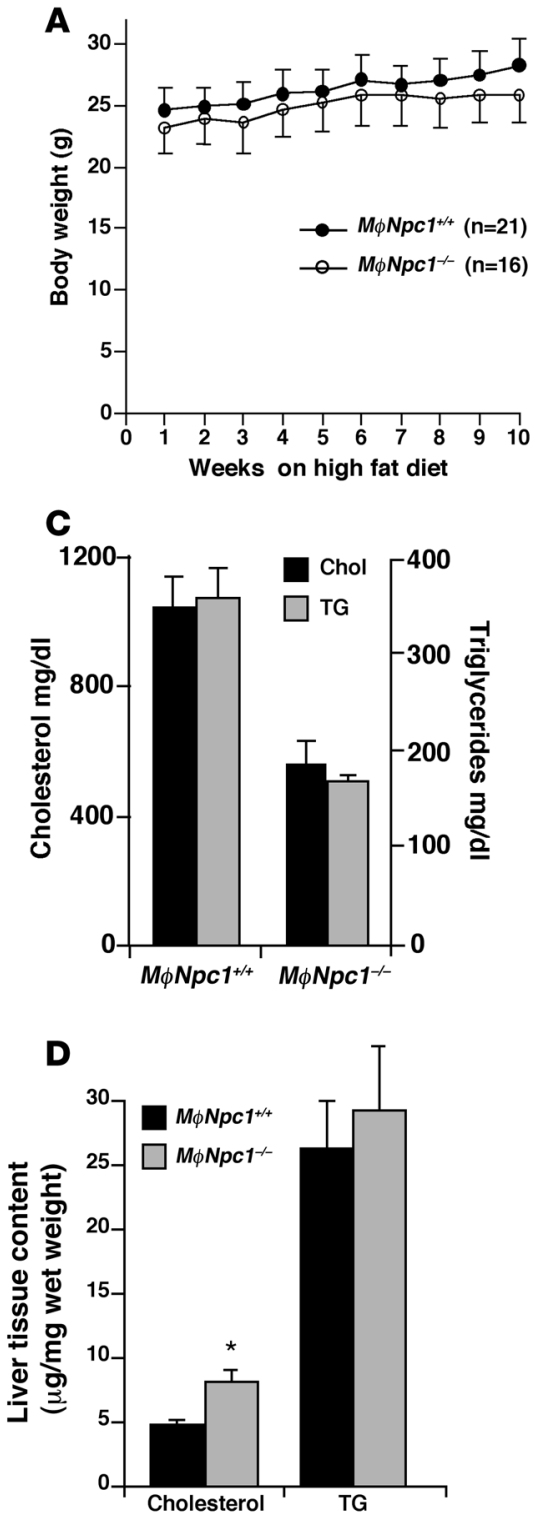
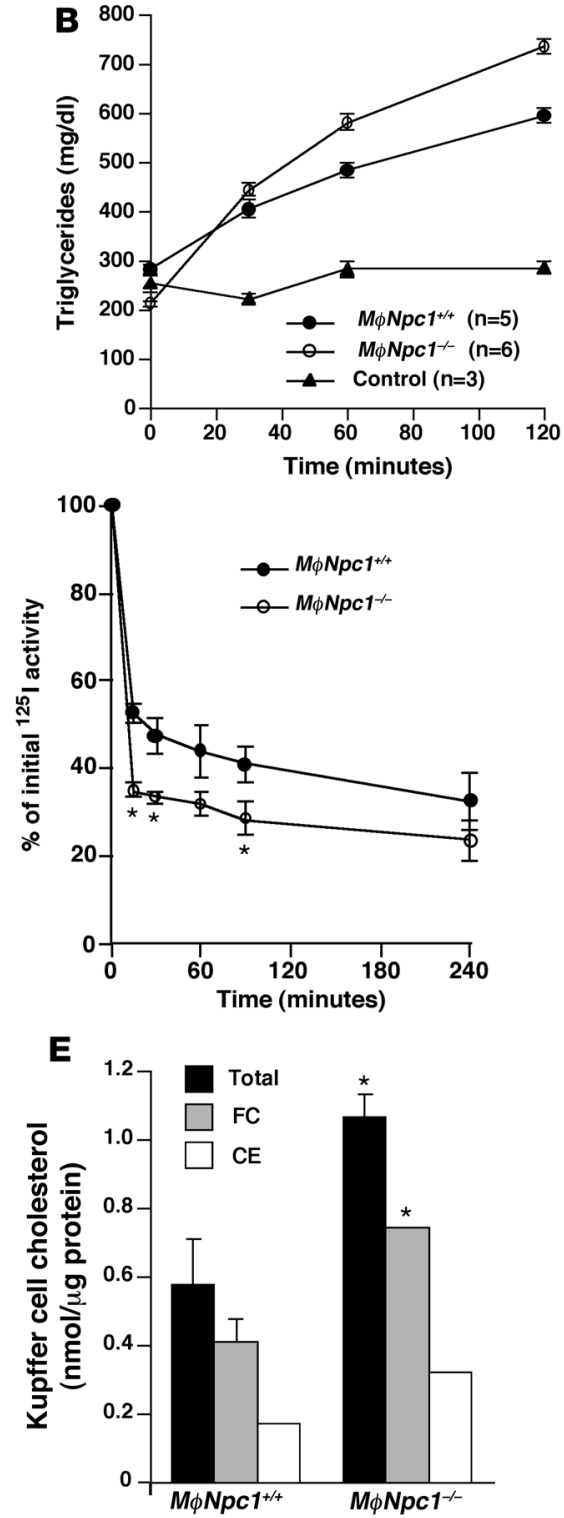

Figure 3

Lipoprotein metabolism studies in $\mathrm{M} \phi N p c 1^{+/+}$and $\mathrm{M} \phi \mathrm{Npc1}^{-/-}$mice fed an atherogenic diet for 10 weeks. (A) Body weight. (B) TG production. Fasting TG levels were determined at time 0 . Mice were injected with Triton WR 1339 to inhibit systemic lipolysis or with PBS control, and venipuncture was performed at 30,60 , and 120 minutes. (C) VLDL clearance. Mice were injected with ${ }^{125}$ I-VLDL, and blood was collected 0-240 minutes after injection. The amount of 125 I-VLDL remaining in plasma at each time point was expressed as a percentage relative to the ${ }^{125}$-radioactivity in the plasma 1 minute after initial injection. (D) Liver tissue cholesterol content ( $n=8-9$ per genotype). (E) Cholesterol content of Kupffer cell fractions isolated from the liver. Fractions from 2 mice per genotype were pooled, lipids were extracted, and cholesterol was measured by GC/MS. FC, free cholesterol; $\mathrm{CE}$, cholesterol ester. For all experiments shown, data are mean \pm SEM of triplicate determinations and are representative of 2 independent experiments. ${ }^{*} P<0.05$ versus $\mathrm{M} \phi N p c 1^{+/+}$. the block imposed by NPC1 loss of function. Taken together, our findings show that failure to activate LXR-mediated responses in macrophages from $\mathrm{M} \phi N p c 1^{-/-}$mice may have contributed to atherosclerotic lesion formation.

LXR ligand deficiency in macrophages from $M \phi N p c 1^{-/-}$mice. Previously we showed that the sterol homeostatic defects in NPC1 mutant cells were associated with a profound decrease in synthesis of LDL-cholesterol-derived oxysterols $(17,18)$. To assess whether decreased production of 27-HC, an endogenous LXR ligand, causes reduced LXR-mediated cholesterol efflux, we measured oxysterol production in peritoneal macrophages in response to acetylated LDL (AcLDL) cholesterol loading. While mRNA levels of CYP27A1, the mitochondrial sterol 27-hydroxylase responsible for conversion of cholesterol to $27-\mathrm{HC}$, were equivalent in macrophages isolated from $\mathrm{M} \phi N p c 1^{+/+}$and $\mathrm{M} \phi N p c 1^{-/-}$mice (data not shown), synthesis of 27-HC and its oxidation product, cholestenoic acid, were reduced in $\mathrm{Npc1}^{-/-}$macrophages by $52 \%$ and $64 \%$, respectively $(P<0.05$; Figure $6 \mathrm{~A})$. Similar reductions in $27-\mathrm{HC}$ syn- thesis were observed in non-lipoprotein-fed $\mathrm{Npc1}^{-/-}$macrophages (data not shown), indicating that lipoprotein-associated oxysterols did not substantially contribute to $27-\mathrm{HC}$ levels. Moreover, in the plasma of high-fat diet-fed $\mathrm{M} \phi N p c 1^{-/-}$mice, total 27-HC levels were reduced by $43 \%\left(\mathrm{M} \phi N p c 1^{+/+}, 541 \pm 2.5 \mathrm{ng} / \mathrm{ml}\right.$; $\mathrm{M} \phi N p c 1^{-/-}$, $310 \pm 0.34 \mathrm{ng} / \mathrm{ml} ; P<0.05)$, and free $27-\mathrm{HC}$ levels were reduced by $24 \%\left(\mathrm{M} \phi N p c 1^{+/+}, 145 \pm 5.5 \mathrm{ng} / \mathrm{ml} ; \mathrm{M} \phi N p c 1^{-/-}, 111 \pm 2.4 \mathrm{ng} / \mathrm{ml}\right.$; $P<0.05$; Figure 6B). Total plasma $27-\mathrm{HC}$ is representative of the vast majority of $27-\mathrm{HC}$ that is esterified and lipoprotein associated, whereas free $27-\mathrm{HC}$ is more representative of the non-lipoprotein-associated $27-\mathrm{HC}(25,26)$. In light of the rapid hepatic uptake of free $27-\mathrm{HC}$, the reduced circulating levels of free $27-\mathrm{HC}$ in $\mathrm{M} \phi N p c 1^{-/-}$mice likely reflect lower rates of $27-\mathrm{HC}$ synthesis by tissue macrophages, the principal source of circulating $27-\mathrm{HC}$ (27), and not simply lower serum lipoprotein levels.

Increased oxidative stress in $\mathrm{Npc1}^{-/-}$macrophages. In addition to the deficiency in enzymatic synthesis of 27-HC, $\mathrm{Npc1}^{-/-}$mouse tissues exhibit increased nonenzymatic oxidation (i.e., autoxidation) of cel- 


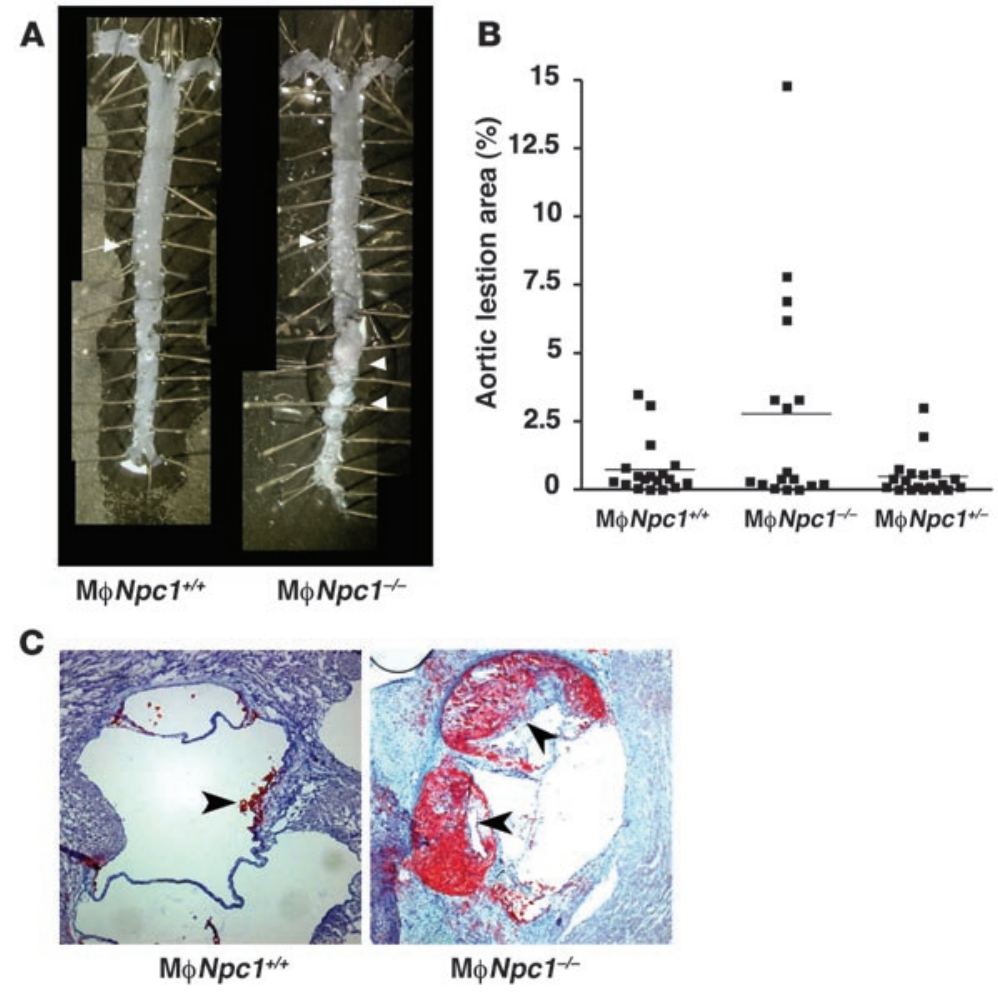

Figure 4

Aortic atherosclerosis in $\mathrm{M} \phi N p c 1^{+/+}$and $\mathrm{M} \phi N p c 1^{-/-}$mice after 10 weeks on a high-fat diet. (A) En face images of representative aortas. Arrows denote atherosclerotic plaque. (B) Quantification of aortic intimal lesions. For each aorta, separate measurements of lesion area were performed in the arch, thoracic aorta, and abdominal aorta. Combined lesion area was significantly greater in $\mathrm{M} \phi N p c 1^{-/-}$than in $\mathrm{M} \phi N p c 1^{+/+}$mice $(P<0.05)$. (C) Atherosclerosis at aortic origin. Frozen aortic cross-sections from representative high-fat diet-fed $\mathrm{M} \phi N p c 1^{+/+}$and $\mathrm{M} \phi N p c 1^{-/-}$chimeric mice were stained with hematoxylin and Oil red O. Arrows indicate regions staining for Oil red $O$. Original magnification, $\times 10(\mathbf{A}) ; \times 100(\mathbf{C})$. lular cholesterol, resulting in a several-fold increase in total cholesterol oxidation products (28). Autoxidation products, which include steroid ring-modified 5,6- and 7-oxygenated compounds (29), have been reported to be cytotoxic in vitro and proposed to contribute to atherogenesis (30). We therefore monitored for the presence of the cholesterol oxidation products in the plasma of $\mathrm{M} \phi \mathrm{Np}_{\mathrm{p} 1^{+/+}}$ and $\mathrm{M} \phi N p c 1^{-/-}$mice and in conditioned media and cell extracts of lipoprotein-fed peritoneal macrophages harvested from the chimeric mice. Total cholesten-3 $\beta, 5 \alpha, 6 \beta$-triol (an oxidation product of both $5 \alpha, 6 \alpha$-epoxycholesterol and $5 \beta, 6 \beta$-epoxycholesterol), $7 \beta-\mathrm{HC}$, and 7-ketocholesterol levels in plasma from $\mathrm{M} \phi N p c 1^{-/-}$mice were respectively 3.7-, 2.2-, and 1.15-fold those of $\mathrm{M} \phi N p c 1^{+/+}$mice $\left(P<0.05\right.$; Figure 7A). Levels of cell-associated oxysterols in $\mathrm{M} \phi \mathrm{Npc1}^{-1}$ macrophages were uniformly elevated for all oxysterols examined (Figure 7B), even among enzymatically generated side-chain oxysterols 24-HC, 25-HC, and 27-HC, for which total oxysterol synthesis (media plus cell-associated oxysterols) was reduced (Figure $6 \mathrm{~A})$. For the oxysterol panel measured in the cell extracts, total cellular oxysterols were $3.67 \mu \mathrm{g} / \mathrm{mg}$ protein in $\mathrm{Npc1}^{-/-}$macrophages, compared with $1.42 \mu \mathrm{g} / \mathrm{mg}$ protein in $\mathrm{M} \phi N p c 1^{+/+}$macrophages, consistent with the oxysterol accumulation previously reported in $\mathrm{NpC1}^{-/-}$murine tissues (28). The intracellular accumulation of oxysterols may reflect impaired oxysterol efflux due to reduced expression of LXR-activated sterol transporters. Recent reports showing that 7-ketocholesterol, 25-HC, and 27-HC accumulate in ABCG1-, ABCA1-, and ABCG1/ABCG4-deficient cells, respectively, support such a mechanism (31-33). Whether the elevated levels of nonenzymatic cholesterol autoxidation products, which have been shown to be cytotoxic in vitro, also contribute to atherogenesis in vivo, or are simply markers of oxidative stress, is not known.

Cholesterol autoxidation products are formed through the interaction of cholesterol with ROS (34). To determine whether increased ROS generation is responsible for the elevated oxysterol levels in the $\mathrm{Npc1}^{-/-}$macrophages, we measured cell fluorescence following loading with 6-carboxy-2',7'-dichlorodihydrofluorescein diacetate $\left(\mathrm{H}_{2} \mathrm{DCFDA}\right)$, a fluorescent, membrane-permeable probe widely used as a marker of ROS in cells (35). We found increased ROS generation in the M $\phi N p c 1^{-/-}$macrophages, 2.2-fold that of $\mathrm{M} \phi N \mathrm{pc}^{+/+}$macrophages, indicative of increased cellular oxidative stress (Figure 7C). Protein carbonyl levels, a marker of cumula-

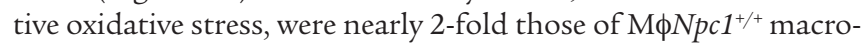
phages, providing further support for increased ROS generation in M $\phi N p c 1^{-1-}$ cells (Figure 7D). Treatment with T0901317, a synthetic oxysterol LXR ligand previously shown to upregulate ABCA1 expression and cholesterol efflux in $N p c 1^{-/-}$fibroblasts $(24,36)$, reduced ROS accumulation by $38 \%$, partially suppressing oxidative stress in the $\mathrm{M} \phi N p c 1^{-/-}$macrophages (Figure 7C).

\section{Discussion}

In this study we investigated the role of NPC1-mediated cholesterol trafficking in regulation of macrophage cholesterol homeostasis. Using BMT to disrupt NPC1 expression in macrophages of $L d r^{-/}$mice, we demonstrated that absence of NPC1 expression was proatherogenic in vivo. Deletion of Npc1 in BM-derived cells accelerated atherosclerosis by impairing cholesterol efflux and promoting cellular oxidative stress. The $\mathrm{NpC1}^{-/-}$chimeric mice exhibited increased atherosclerotic lesion formation despite lower cholesterol and TG levels in the VLDL and LDL fractions. The discordance observed between serum cholesterol and the extent of atherosclerosis underscores the central role of the NPC cholesterol trafficking pathway in regulation of macrophage lipid metabolism and modulating the susceptibility of these cells to oxidative stress.

Previous studies have shown that $\mathrm{Npc1}^{-/-}$cells in culture have impaired cholesterol efflux. The lysosomal sequestration of LDL- 

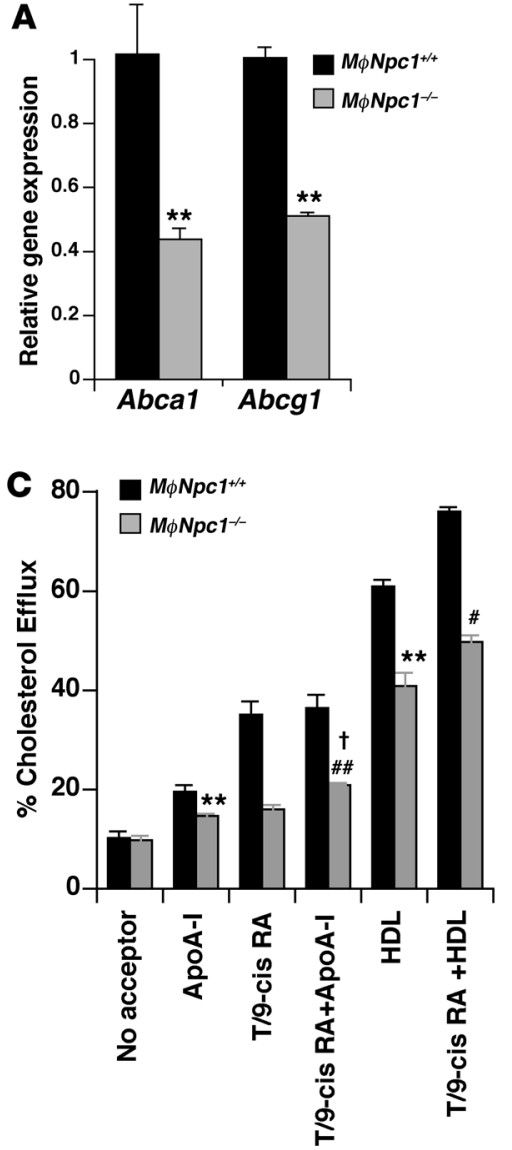

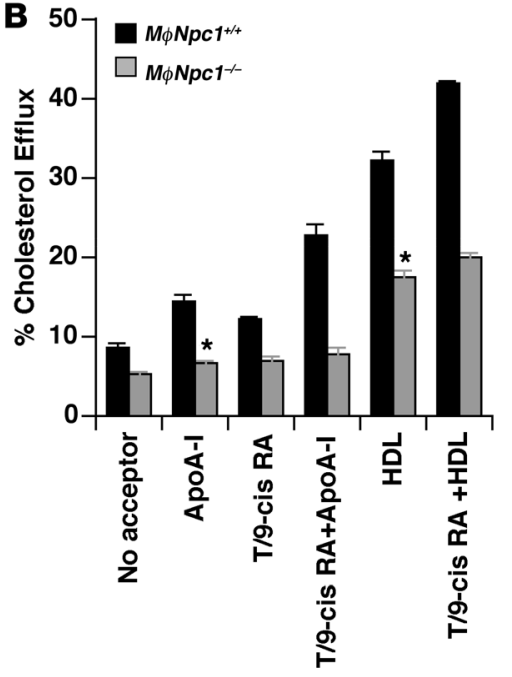

Figure 5

Reduced expression of cholesterol transporters and cholesterol efflux in $\mathrm{M} \phi N p c 1^{-/-}$chimeric mice. (A) $A b c a 1$ and $A b c g 1$ gene expression in peritoneal macrophages harvested from high-fat diet-fed $\mathrm{M} \phi N p c 1^{+/+}$and $\mathrm{M} \phi \mathrm{Npc1}^{-/-}$mice. Expression was determined by realtime quantitative RT-PCR and normalized to expression in $\mathrm{M} \phi \mathrm{Npc1}^{+/+}$macrophages. (B and $\mathbf{C}$ ) Cholesterol efflux to apoA-I and HDL from peritoneal macrophages harvested from high-fat diet-fed $\mathrm{M} \phi \mathrm{Npc1}^{+/+}$and $\mathrm{M} \phi N p \mathrm{N1}^{-/-}$ mice. Cells were incubated overnight with AcLDL labeled with $\left[{ }^{3} \mathrm{H}\right]$ cholesterol, followed by incubation for 4 (B) or 24 hours (C) in medium containing $0.2 \%$ BSA with $10 \mu \mathrm{g} / \mathrm{ml}$ human apoA-l or $50 \mu \mathrm{g} / \mathrm{ml}$ human HDL. ApoA-I- or HDL-specific cholesterol efflux is shown as the radioactivity released from the cells into the medium, expressed as a percentage relative to the total radioactivity in cells and media. T/9-cis RA, T0901317. Data are mean \pm SEM of triplicate determinations and are representative of 2 independent experiments. ${ }^{*} P \leq 0.05$, ${ }^{* *} P \leq 0.01$ versus respective $\mathrm{M} \phi N p c 1^{+/+} ;{ }^{\#} P \leq 0.05$, $\# P \leq 0.01$ versus respective untreated $\mathrm{M} \phi N p c 1^{-1-}$; ${ }^{\dagger} P=\mathrm{NS}$ versus untreated ApoA-I M $\phi N p c 1^{+/+}$. derived cholesterol affects efflux activity by limiting cholesterol substrate for ABCA1-dependent efflux and by failing to appropriately generate LDL-cholesterol-derived side-chain oxysterols (15, $17,18)$. In $\mathrm{Npc1}^{-/-}$cells, decreased production of side-chain oxysterols, which serve as endogenous LXR ligands, results in reduced ABCA1 protein expression and lower cholesterol efflux activity (16, 24). Thus, in cultured cells NPC1-mediated cholesterol trafficking participates in regulation of LXR sterol homeostatic responses. In the present study, we provide evidence that the NPC1 cholesterol trafficking pathway regulates LXR-dependent cholesterol efflux in vivo, alleviating cholesterol-induced oxidative stress and serving an atheroprotective role.
While the function of NPC1 in distribution of free cholesterol from the late endocytic pathway is well characterized, little is known of the macrophage-specific role of NPC1 in regulating sterol homeostasis in vivo and in modulating susceptibility to atherosclerosis. A previous study that examined the effect of $N p c 1$ deficiency on atherogenesis did not find differences in aortic lesional area in high-fat diet-fed $\mathrm{NpC1}^{+/-} \mathrm{Apoe}^{-/-}$mice compared with Apoe-/- mice, although NPC1 heterozygosity was associated with resistance to lesional necrosis and lesional macrophage apoptosis (37). More recently, Welch et al. reported that introduction of the $\mathrm{Npc1}^{-/-}$mutation into the Apoe $e^{-/-}$ background predisposed to increased lesion formation and atherothrombosis (23). In agreement with these studies, we found that NPC1
Figure 6

$\mathrm{NpC1}^{-/-}$macrophages are deficient in production of endogenous oxysterol ligands. (A) Production of $27-\mathrm{HC}$ and cholestenoic acid in macrophages harvested from high-fat diet-fed $\mathrm{M} \phi \mathrm{Npc}^{+/+}$and $\mathrm{M} \phi N p c 1^{-/-}$chimeric mice. Macrophages were cultured in lipoprotein-deficient medium followed by overnight incubation with $50 \mu \mathrm{g} / \mathrm{ml}$ AcLDL. Lipids were extracted from media, and cells and oxysterols were measured by GC/MS. Data are mean \pm SEM and are representative of 2 independent experiments. (B) Plasma oxysterol levels in high-fat diet-fed $\mathrm{M} \phi N p c 1^{+/+}$and $\mathrm{M} \phi N p c 1^{-/-}$ chimeric mice. Sera from 5-6 animals per genotype were pooled and analyzed by GC/MS. Data are mean \pm SEM of triplicate determinations and are representative of 2 independent experiments. ${ }^{*} P<0.05$ versus $\mathrm{M} \phi N p c 1^{+/+}$.
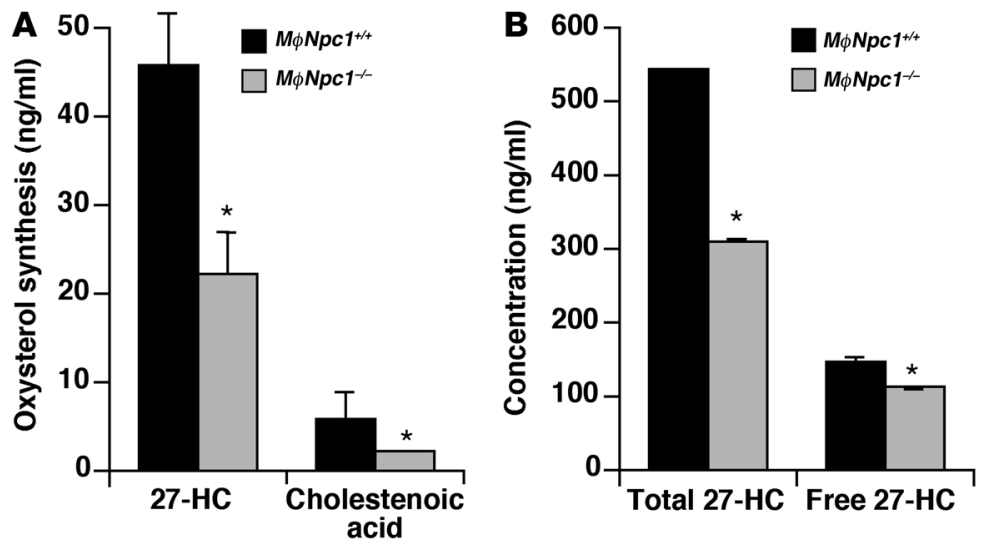

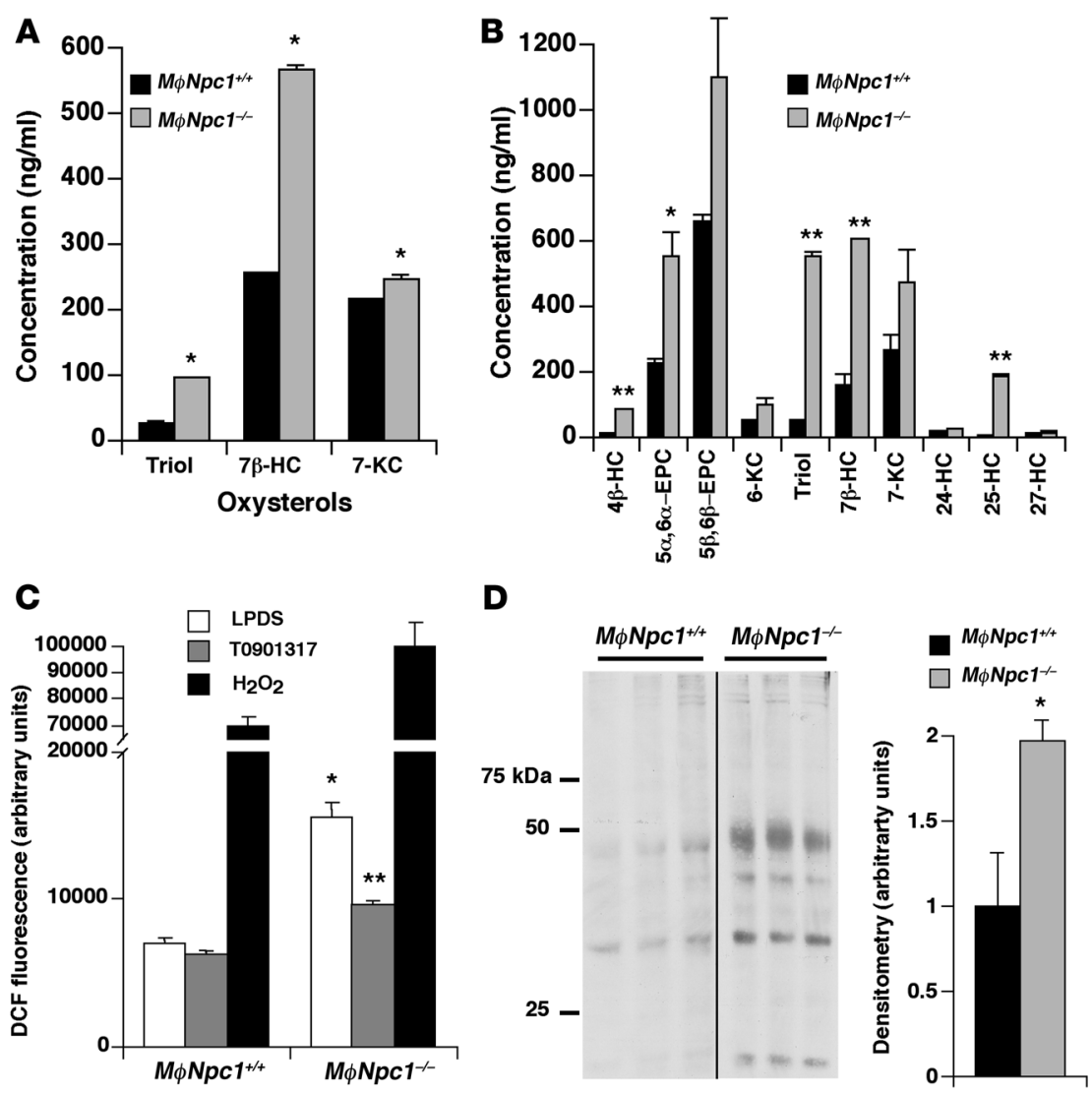

D

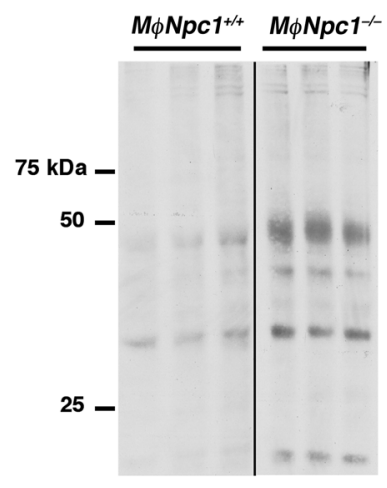

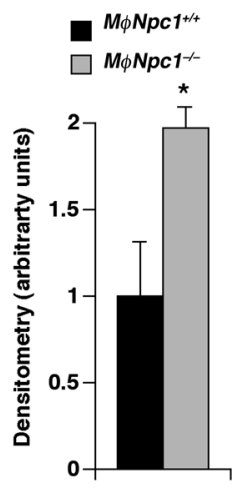

\section{Figure 7}

Oxidative stress in high-fat diet-fed $\mathrm{M} \phi N p c 1^{+/+}$ and $\mathrm{M} \phi N p c 1^{-/-}$mice. (A) Plasma levels of cholesterol autoxidation products. Sera from 5-6 animals per genotype were pooled and analyzed by $\mathrm{GC} / \mathrm{MS}$. Data are mean \pm SEM for triplicate measurements and are representative of 2 independent experiments. (B) Levels of cell-associated oxysterols in harvested macrophages. Lipids were extracted from cells, and oxysterols were measured by GC/MS. Data are mean \pm SEM for triplicate measurements and are representative of 2 independent experiments. (C) Measurement of ROS in harvested macrophages. Macrophages were cultured overnight in lipoprotein-deficient serum (LPDS) in the presence or absence of $10 \mu \mathrm{M}$ T0901317 and incubated for 30 minutes with $10 \mu \mathrm{M} \mathrm{H}_{2}$ DCFDA, after which fluorescence was determined. Data are mean \pm SEM for triplicate measurements and are representative of 2 independent experiments. (D) Oxidative damage in harvested macrophages was assessed by measuring protein carbonylation in cell lysates. Ponceau S staining served as a loading control. Data are mean \pm SEM and are representative of 2 independent experiments. ${ }^{*} P<0.05,{ }^{*} P<0.01$ versus respective $\mathrm{M} \phi N p c 1^{+/+}$. loss of function, but not NPC1 haploinsufficiency, promoted aortic atherosclerosis in mice fed the high-fat diet. We further extended these earlier reports by demonstrating the selective role of $\mathrm{Npc1}^{-/-}$ $\mathrm{BM}$-derived cells to the proatherosclerotic phenotype and by elucidating the contribution of the NPC cholesterol trafficking pathway in vivo to LXR-dependent cholesterol efflux in macrophages. Given the high level of NPC1 expression in the monocyte/macrophage lineage and the importance of these cells to lipoprotein metabolism, it is probable that deletion of $N p c 1$ in macrophages is primarily responsible for the accelerated atherosclerosis, although the contribution of non-macrophage BM-derived cells cannot be excluded. Because complete disruption of NPC1 expression is required to increase susceptibility to atherosclerosis, we conclude that the protective effect of NPC1-mediated cholesterol trafficking is not gene dose dependent.

We propose that decreased mitochondrial conversion of lipoprotein cholesterol to $27-\mathrm{HC}$ in the $\mathrm{Npc1}^{-1-}$ macrophages is the principal mechanism for accelerated atherosclerosis in the M $\phi N p c 1^{-1-}$ model. Decreased 27-HC levels, which have been reported previously in other $N p c 1^{-/-}$cell types $(17,18)$, may reflect impaired delivery of cholesterol substrate to the inner mitochondrial membrane for side-chain oxysterol synthesis. However, recent reports showing that mitochondrial membranes in $\mathrm{Npc1}^{-/-}$cells are enriched in cholesterol $(38,39)$ indicate that the consequence of NPC1 loss of function may be more complex than failure of bulk cholesterol delivery to the mitochondria. Despite the endosomal cholesterol trafficking defect, cholesterol transport to mitochondria is enhanced in $\mathrm{Npc1}^{-/-}$cells, leading to inhibition of ATP synthase activity (38). Free cholesterol loading of the mitochondria could prevent transfer of cholesterol from the outer to inner mitochondrial membranes, where oxysterol synthesis occurs, or could inhibit sterol 27-hydroxylase enzymatic activity directly. It is likely that the lower 27-HC levels observed in $\mathrm{NpC1}^{-1-}$ macrophages result from decreased oxysterol synthesis rather than enhanced catabolism of 27-HC, because we did not observe a commensurate increase in the levels of known oxidation products of $27-\mathrm{HC}$, such as cholestenoic acid (Figure $6 \mathrm{~A}$ ), or of $7 \alpha, 27-\mathrm{HC}$ or $7 \beta, 27-\mathrm{HC}$ (ref. 40 and data not shown). In $\mathrm{Npc1}^{-/-}$macrophages, deficiency of 27-HC, which is known to activate LXR gene expression and has been proposed as an endogenous LXR ligand (4-6), is associated with decreased expression of the ABCA1 and ABCG1 sterol transporters, impaired cholesterol efflux, and lower serum HDL levels. Therefore, in the $\mathrm{Npc1}^{-/-}$macrophages, we conclude that $27-\mathrm{HC}$ deficiency is responsible for decreased LXR activation and contributes to atherosclerotic lesion formation by failing to stimulate cellular cholesterol efflux. To the best of our knowledge, our findings are the first to implicate deficiency of an endogenous LXR ligand in vivo in the development of atherosclerosis.

Our findings support a central role for NPC1 in macrophage reverse cholesterol transport. By directing a portion of the lipoprotein-derived cholesterol to sites of oxysterol synthesis, the NPC pathway is responsible for generation of endogenous LXR ligands that govern expression of the ABCA1 and ABCG1 cell surface sterol transporters. In macrophages, $\mathrm{ABCA} 1$ and $\mathrm{ABCG} 1$ act in concert to facilitate to reverse cholesterol transport initially through lipidation of nascent apoA-I, followed by its subsequent remodeling into mature, spheroidal HDL (41). In previous BMT studies, combined deletion of ABCA1 and ABCG1 led to a massive lipid accumulation in macrophages that was far more dramatic than occurred 
with deletion of either ABCA1 or ABCG1 alone (42-46). Thus, the profound atherosclerotic phenotype in the mice with deletion of $N p c 1$ in BM-derived cells appears to reflect the upstream role of the NPC cholesterol trafficking pathway for induction of these LXRactivated sterol transporters.

Increased oxidative stress in the $\mathrm{Npc1}^{-/-}$macrophages may also have contributed to atherosclerotic lesion formation in vivo. The etiology of elevated ROS generation and oxidative damage in the $\mathrm{Npc1}^{-1-}$ macrophages does not appear to relate to ER stress, because no increase was found in expression of ER stress markers grp78, calreticulin, or CCAAT/enhancer-binding protein homologous protein (CHOP) (data not shown). Rather, increased ROS may be a consequence of free cholesterol-mediated mitochondrial dysfunction. In addition to inhibition of ATP synthase activity and loss of membrane potential, cholesterol accumulation in mitochondrial membranes is associated with mitochondrial glutathione depletion, which sensitizes cells to oxidative stress $(38,39)$. ROS generated by oxidative stress are a well-established signal for activation of NF- $\mathrm{\kappa B}$, a key transcription factor in the induction of inflammatory mediators (47). Thus, induction of NF-кB-dependent pathways, possibly involving lipoprotein oxidation and inflammatory cell recruitment, may have accelerated atherosclerosis in the chimeric $\mathrm{M} \phi N p c 1^{-/-}$model (48).

Under conditions of cholesterol excess, the mitochondria likely serve as an important link between LXR-dependent pathways and modulation of oxidative stress in macrophages. In $\mathrm{NpC1}^{-/-}$macrophages, decreased oxysterol synthesis by the mitochondrial sterol 27-hydroxylase resulted in failure to activate LXR-dependent gene expression and cholesterol efflux, further exacerbating free cholesterol-induced mitochondrial dysfunction and promoting oxidative stress. The accumulation of cholesterol autoxidation products in the $\mathrm{Npc1}^{-{ }^{--}}$macrophages may be caused not only by the highly oxidative intracellular milieu, but also by decreased oxysterol export by the LXR-regulated ABCA1 sterol transporter (31). An unexpected finding in our study was that treatment with the synthetic LXR ligand attenuated ROS generation. These results suggest that pharmacological activation of LXR pathways in macrophages provides atheroprotection both by lowering cellular cholesterol and by suppressing mitochondria-mediated oxidative stress.

Because human NPC1 disease is a rare disorder that is generally fatal in the first 2 decades of life, the incidence of atherosclerotic disease in affected individuals or in obligate heterozygotes is not known. Given the pathophysiological effects of disruption of NPC1 function in macrophages, we speculate that polymorphisms in the NPC1 gene may modulate atherosclerosis susceptibility. In light of our findings that plasma 27-HC levels correlated with impaired 27-HC synthesis in the cultured macrophages, detection of altered circulating levels of this proposed physiological LXR ligand $(5,6)$ may provide important insight into cholesterol metabolism in the vessel wall. In particular, plasma levels of 27-HC and other oxysterol species potentially could serve as novel biomarkers to facilitate early detection and stratification of human subjects at risk for atherosclerotic disease.

\section{Methods}

Mice. $\mathrm{BALB} / \mathrm{c} \mathrm{Np}^{\text {nih }}$ mice were obtained from The Jackson Laboratory, backcrossed 8 generations into the $\mathrm{C} 57 \mathrm{BL} / 6$ background, and then intercrossed with C57BL/6 Ldlr/- Ly 5.1 mice to generate BMT donors with the following genotypes: $\mathrm{Npc1}^{-/-} \mathrm{Ldlr} /-\mathrm{Ly} 5.1, \mathrm{Npc1}^{+/-} \mathrm{Ldlr} /-\mathrm{Ly} 5.1$, and $\mathrm{Npc1}^{+/+}$
$L d l r^{-}$Ly5.1. Experimental procedures were approved by the Washington University Animal Studies Committee and were conducted in accordance with the USDA Animal Welfare Act and the Public Health Service Policy for the Humane Care and Use of Laboratory Animals.

BMT. BM was harvested from sex-matched $\mathrm{Npc1}^{-/-} \mathrm{Ldlr} \mathrm{r}^{-/}$Ly5.1, $\mathrm{NpC1}^{+/-}$ Ldlr/- Ly5.1, and $\mathrm{Npcl}^{+/+} \mathrm{Ldlr}^{-/-}$Ly5.1 donors by flushing the femurs and tibias with PBS. Male C57BL/6 Ldlr ${ }^{-1}$ Ly5.2 recipients (4-6 weeks old) were lethally irradiated with $10 \mathrm{~Gy}$ from a ${ }^{137} \mathrm{Cs}$ source, followed by tail vein injection with $10^{6} \mathrm{BM}$ cells. Prophylactic antibiotics (sulfamethoxazole and trimethoprim) were administered for 2 weeks after BMT. At 6 weeks after BMT, peripheral blood was obtained from recipients, and cells were stained with anti-CD45.1 and anti-CD45.2 to identify Ly5.1and Ly5.2-positive cells by flow cytometry, as previously described (21), to evaluate the reconstitution.

High-fat diet feeding. Transplanted mice with greater than $75 \%$ reconstitution were placed on a high-fat diet containing $0.15 \%$ cholesterol and providing $42 \%$ calories as fat (TD 88137; Harlan Teklad). Serum cholesterol and TG measurements were performed at $0,3,6$, and 10 weeks after initiation of high-fat diet feeding. Mice were fasted for 4 hours prior to blood draws. Sera of mice fed the high-fat diet for 10 weeks were pooled to obtain lipoprotein profile by fast protein liquid chromatography (FPLC) (49). High-sensitivity lipoprotein profiling was performed using the LipoSEARCH method by Skylight Biotech Inc. (50).

Atherosclerotic lesion quantification. Lesion area was determined as described previously (51). Digital images of pinned aortas were analyzed using an image-processing program. Lesional areas were determined as the percentage of involvement of the intimal surface area for the arch (extending from the aortic valve to a point just distal to the left subclavian artery), the thoracic aorta (extending to the last intercostal artery), and the abdominal aorta (extending to the ileal bifurcation).

Immunocytochemistry. Hearts were frozen in Tissue-Tek OCT compound, and sections were obtained through the aorta root. Frozen sections were fixed with acetone, and immunohistochemistry was performed as described previously (49). Sections were stained with Oil red O and Mac-3 to detect neutral lipids and macrophages, respectively. Cholesterol staining of peritoneal macrophages was performed using $B C-\Theta$, a FITC-conjugated derivative of perfingolysin $\mathrm{O}(\Theta$ toxin) (52).

Lipoprotein metabolism. VLDL clearance was performed as described previously (53). Briefly, VLDL was obtained from pooled donor $L d l r^{-/}$mice and labeled with ${ }^{125} \mathrm{I}$ to produce ${ }^{125} \mathrm{I}$-VLDL. Unincorporated ${ }^{125} \mathrm{NaI}$ was removed with PD-10 columns, and FPLC was used to isolate the VLDLspecific fraction. Mice were anesthetized and injected with a $0.2-\mathrm{ml}$ bolus of ${ }^{125} \mathrm{I}-\mathrm{VLDL}$, and blood was subsequently collected at regular intervals. Data at each time point are presented as the mean from at least 3 different animals. VLDL synthesis rates were determined by inhibiting intravascular lipolysis with Triton WR 1339 (54). After measurement of baseline TGs, fasted mice were injected with WR $1339(60 \mathrm{mg} / \mathrm{kg})$ or PBS, and serum TGs were determined at 30,60 , and 120 minutes.

Cholesterol absorption assay. For cholesterol absorption studies, mice were maintained on sterol-deficient chow diet for 2 days before gavage with $0.1 \mathrm{ml}$ soybean oil containing $0.0625 \mathrm{mg} \mathrm{d}_{4}$-sitostanol and $0.25 \mathrm{mg}$ $\mathrm{d}_{7}$-cholesterol. Feces were collected for 3 days. Sterols were purified from feces and measured by gas chromatography/mass spectrometry (GC/MS) as described previously (55). The percent of $\mathrm{d}_{7}$-cholesterol in the stool was calculated from each tracer recovered relative to the respective total amount administered.

Kupffer cell isolation. Kupffer cells were isolated from liver tissue using a 2-step collagenase-dispase perfusion method as previously described (56).

Real-time quantitative RT-PCR. RNA isolation, cDNA synthesis, and realtime PCR using SYBR Green Master Mix with template-specific primers 
was performed as described previously (24). Fold changes in gene expression were determined by normalization to $36 \mathrm{~B} 4$ expression.

Cholesterol efflux assay. Thioglycollate-elicited peritoneal macrophages were harvested as described previously (57). Macrophages were incubated with $\left[{ }^{3} \mathrm{H}\right]$ cholesterol-labeled AcLDL, followed by incubation for 4 hours in medium containing $0.2 \% \mathrm{BSA}$ and $10 \mu \mathrm{g} / \mathrm{ml}$ human apoA-I or $50 \mathrm{mg} / \mathrm{ml}$ human HDL. ApoA-I- and HDL-specific cholesterol efflux were calculated as the radioactivity released from the cells into the medium, expressed as a percentage relative to total radioactivity in cells and media.

Oxysterol determinations. Thioglycollate-elicited peritoneal macrophages were harvested as described above. Macrophages were grown in DMEM plus $10 \%$ FBS for 4 hours and then changed to DMEM with $10 \%$ lipoprotein-deficient serum. Macrophages were refed DMEM with $10 \%$ lipoprotein-deficient medium containing $50 \mu \mathrm{g} / \mathrm{ml} \mathrm{AcLDL}$ overnight, followed by harvest of medium and cells for lipid extraction. Oxysterols were extracted from the media and measured by GC/MS as previously described using 200 pmol deuterated 27-HC $\left(\mathrm{d}_{5}-27-\mathrm{HC}\right)$ as an internal standard (17). Quantitative GC/MS determinations for oxysterol species were calculated from triplicate injections. Total cellular proteins were extracted with $0.1 \mathrm{~N} \mathrm{NaOH}$ and quantified using the BCA assay, and oxysterol measurements were normalized to the total protein values. For serum oxysterol measurements, pooled sera of 5-6 animals per genotype were divided into $2250-\mu 1$ fractions and analyzed by GC/MS. The free and total samples were processed identically, except that the total samples underwent saponification (1 hour at room temperature) prior to oxysterol isolation to hydrolyze sterol esters (58). Oxysterol determinations were performed as described above.

Detection of ROS. Cellular levels of ROS were determined as previously described (35). Peritoneal macrophages were harvested as described previously (57) and plated in DMEM plus 10\% FBS. Cells were washed in
PBS and incubated for 30 minutes with PBS containing $0.5 \mathrm{mM} \mathrm{MgCl}_{2}$, $0.92 \mathrm{mM} \mathrm{CaCl}_{2}$, and $10 \mu \mathrm{M} \mathrm{H}_{2}$ DCFDA. Fluorescence was determined using a fluorescent plate reader.

Measurement of protein carbonylation. Macrophages were harvested as described above. Detection of the formation of carbonyl groups in proteins was performed according to the manufacturer's instructions using the OxyBlot oxidized protein detection kit (Chemicon International).

Statistics. Results are expressed as mean \pm SEM. The statistical significance of differences in mean values was determined by single-factor ANOVA or Student's $t$ test. A $P$ value of 0.05 or less was considered significant.

\section{Acknowledgments}

This work was supported by Washington University Specialized Centers of Clinically Oriented Research grant P50 HL083762. The authors received support from the Washington University/ Pfizer Biomedical Research Program, the Ara Parseghian Medical Research Foundation, and NIH grant HL067773 (to D.S. Ory); from NIH grant DK076729 (to C.F. Semenkovich); from NIH grant DK064989 (to J.E. Schaffer); and from NIH grant DK57586 (to M.S. Sands). Support was also provided by NIH grants P30 DK52574, P60 DK020579, P30 DK56341, and RR020643.

Received for publication May 2, 2007, and accepted in revised form April 9, 2008.

Address correspondence to: Daniel S. Ory, Center for Cardiovascular Research, Washington University School of Medicine, Box 8086, 660 S. Euclid Avenue, St. Louis, Missouri 63110, USA. Phone: (314) 362-8737; Fax: (314) 362-0186; E-mail: dory@wustl.edu.
1. Ory, D. 2004. Nuclear receptor signaling in control of cholesterol homeostasis: Have the orphans found a home? Circ. Res. 95:660-670.

2. Ory, D.S. 2004. The Niemann-Pick disease genes: regulators of cellular cholesterol homeostasis. Trends Cardiovasc. Med. 14:66-72.

3. Chawla, A., Repa, J.J., Evans, R.M., and Mangelsdorf, D.J. 2001. Nuclear receptors and lipid physiology: opening the X-files. Science. 294:1866-1870.

4. Willy, P.J., et al. 1995. LXR, a nuclear receptor that defines a distinct retinoid response pathway. Genes Dev. 9:1033-1045.

5. Fu, X., et al. 2001. 27-hydroxycholesterol is an endogenous ligand for liver $\mathrm{X}$ receptor in cholesterol-loaded cells. J. Biol. Chem. 276:38378-38387.

6. Chen, W., Chen, G., Head, D.L., Mangelsdorf, D.J., and Russell, D.W. 2007. Enzymatic reduction of oxysterols impairs LXR signaling in cultured cells and the livers of mice. Cell Metab. 5:73-79.

7. Björkhem, I., and Muri-Boberg, K. 1995. Inborn errors in bile acid biosynthesis and storage of sterols other than cholesterol. In The metabolic and molecular bases of inherited disease. 7th edition. C.R. Scriver, et al., editors. McGraw-Hill. New York, New York, USA. 2073-2099.

8. Steinberg, S.J., Mondal, D., and Fensom, A.H. 1996. Co-cultivation of Niemann-Pick type $\mathrm{C}$ fibroblasts belonging to complementation groups $\mathrm{a}$ and $\mathrm{b}$ stimulates LDL-derived cholesrterol esterification. J. Inher. Metab. Dis. 19:769-774.

9. Vanier, M.T., Duthel, S., Rodriguez-Lafrasse, C., Pentchev, P., and Carstea, E.D. 1996. Genetic heterogeneity in Niemann-Pick C disease: a study using somatic cell hybridization and linkage analysis. Am. J. Hum. Genet. 58:118-125.

10. Millard, E.E., Srivastava, K., Traub, L., Schaffer, J.E., and Ory, D.S. 2000. NPC1 overexpression alters cellular cholesterol homeostasis. J. Biol. Chem. 275:38445-38451.
11. Neufeld, E.B., et al. 1996. Intracellular trafficking of cholesterol monitored with a cyclodextrin. J. Biol. Chem. 271:21604-21613.

12. Wojtanik, K.M., and Liscum, L. 2003. The transport of LDL-derived cholesterol to the plasma membrane is defective in NPC1 cells. J. Biol. Chem. 278:14850-14856.

13. Liscum, L., and Faust, J.R. 1987. Low density lipoprotein (LDL)-mediated suppression of cholesterol synthesis and LDL uptake is defective in Niemann-Pick type C fibroblasts. J. Biol. Chem. 262:17002-17008.

14. Pentchev, P.G., et al. 1985. A defect in cholesterol esterification in Niemann-Pick disease (type C) patients. Proc. Natl. Acad. Sci. U. S. A. 82:8247-8251.

15. Chen, W., et al. 2001. Preferential ATP-binding cassette transporter A1-mediated cholesterol efflux from late endosomes/lysosomes. J. Biol. Chem. 276:43564-43569.

16. Choi, H.Y., et al. 2003. Impaired ABCA1-dependent lipid efflux and hypoalphalipoproteinemia in human Niemann-Pick type C disease. J. Biol. Chem. 278:32569-32577.

17. Frolov, A., et al. 2003. NPC1 and NPC2 regulate cellular cholesterol homeostasis through generation of LDL-derived oxysterols. J. Biol. Chem. 278:25517-25525.

18. Zhang, J., et al. 2004. The steroidal analog GW707 activates the SREBP pathway through disruption of intracellular cholesterol trafficking. J. Lipid Res. 45:223-231.

19. Morris, M.D., Bhuvaneswaran, C., Shio, H., and Fowler, S. 1982. Lysosome lipid storage disorder in NCTR/BALB/c mice. I. Description of the disease and genetics. Am. J. Pathol. 108:140-149.

20. Ishibashi, S., et al. 1993. Hypercholesterolemia in low density lipoprotein receptor knockout mice and its reversal by adenovirus-mediated gene delivery. J. Clin. Invest. 92:883-893.

21. Liu, F., Poursine-Laurent, J., and Link, D.C. 2000.
Expression of the G-CSF receptor on hematopoietic progenitor cells is not required for their mobilization by G-CSF. Blood. 95:3025-3031.

22. Towler, D.A., Bidder, M., Latifi, T., Coleman, T., and Semenkovich, C.F. 1998. Diet-induced diabetes activates an osteogenic gene regulatory program in the aortas of low density lipoprotein receptordeficient mice. J. Biol. Chem. 273:30427-30434.

23. Welch, C.L., et al. 2007. Spontaneous atherothrombosis and medial degradation in $\mathrm{Apoe}^{-/-} \mathrm{Npc1}^{-/-}$ mice. Circulation. 116:2444-2452.

24. Langmade, S.J., et al. 2006. Pregnane X receptor (PXR) activation: A mechanism for neuroprotection in a mouse model of Niemann-Pick C disease Proc. Natl. Acad. Sci. 103:13807-13812.

25. Burkard, I., von Eckardstein, A., Waeber, G., Vollenweider, P., and Rentsch, K.M. 2007. Lipoprotein distribution and biological variation of 24 S- and 27 -hydroxycholesterol in healthy volunteers. Atherosclerosis. 194:71-78.

26. Duane, W.C., and Javitt, N.B. 1999. 27-hydroxycholesterol: production rates in normal human subjects. J. Lipid Res. 40:1194-1199.

27. Babiker, A., et al. 1999. Elimination of cholesterol as cholestenoic acid in human lung by sterol 27hydroxylase: evidence that most of this steroid in the circulation is of pulmonary origin. J. Lipid Res. 40:1417-1425.

28. Tint, G., et al. 1998. Cholesterol and oxygenated cholesterol concentrations are markedly elevated in peripheral tissue but not in brain from mice with Niemann-Pick type C phenotype. J. Inher. Metab. Dis. 21:853-863.

29. Lund, E., and Bjorkhem, I. 1995. Role of oxysterols in the regulation of cholesterol homeostasis: a critical evaluation. Acc. Chem. Res. 28:241-249.

30. Bjorkhem, I., and Diczfalusy, U. 2002. Oxysterols: friends, foes, or just fellow passengers. Arterioscler. Thromb. Vasc. Biol. 22:734-742. 
31. Tam, S.P., Mok, L., Chimini, G., Vasa, M., and Deeley, R.G. 2006. ABCA1 mediates high-affinity uptake of 25 -hydroxycholesterol by membrane vesicles and rapid efflux of oxysterol by intact cells. Am. J. Physiol. Cell Physiol. 291:C490-C502.

32. Terasaka, N., Wang, N., Yvan-Charvet, L., and Tall, A.R. 2007. High-density lipoprotein protects macrophages from oxidized low-density lipoproteininduced apoptosis by promoting efflux of 7-ketocholesterol via ABCG1. Proc. Natl. Acad. Sci. U. S. A. 104:15093-15098.

33. Wang, N., et al. 2007. ATP-binding cassette transporters G1 and G4 mediate cholesterol and desmosterol efflux to HDL and regulate sterol accumulation in the brain. FASEB J. 22:1073-1082.

34. Smith, L.L. 1981. Cholesterol autoxidation. Plenum Press. New York, New York, USA. 704 pp.

35. Borradaile, N.M., et al. 2006. A critical role for eukaryotic elongation factor 1A-1 in lipotoxic cell death. Mol. Biol. Cell. 17:770-778.

36. Boadu, E., et al. 2006. Correction of apolipoprotein AI-mediated lipid efflux and high density lipoprotein particle formation in human Niemann-Pick type C disease fibroblasts. J. Biol. Chem. 281:37081-37090.

37. Feng, B., et al. 2003. Niemann-Pick C heterozygosity confers resistance to lesional necrosis and macrophage apoptosis in murine atherosclerosis. Proc. Natl. Acad. Sci. U. S. A. 100:10423-10428.

38. Mari, M., et al. 2006. Mitochondrial free cholesterol loading sensitizes to TNF- and Fas-mediated steatohepatitis. Cell Metab. 4:185-198.

39. Yu, W., et al. 2005. Altered cholesterol metabolism in Niemann-Pick type C1 mouse brains affects mitochondrial function. J. Biol. Chem. 280:11731-11739.

40. Axelson, M., and Larsson, O. 1996. 27-hydroxylated low density lipoprotein (LDL) cholesterol can be converted to $7 \alpha, 27$-dihydroxy-4-cholesten-3-one (cytosterone) before suppressing cholesterol production in normal human fibroblasts. J. Biol. Chem. 271:12724-12736.

41. Wang, X., et al. 2007. Macrophage ABCA1 and ABCG1, but not SR-BI, promote macrophage reverse cholesterol transport in vivo. J. Clin. Invest. 117:2216-2224.

42. Aiello, R.J., et al. 2002. Increased atherosclerosis in hyperlipidemic mice with inactivation of ABCA1 in macrophages. Arterioscler. Thromb. Vasc. Biol. 22:630-637.

43. van Eck, M., et al. 2002. Leukocyte ABCA1 controls susceptibility to atherosclerosis and macrophage recruitment into tissues. Proc. Natl. Acad. Sci. U. S. A 99:6298-6303.

44. Out, R., et al. 2007. Total body ABCG1 expression protects against early atherosclerotic lesion development in mice. Arterioscler. Thromb. Vasc. Biol. 27:594-599.

45. Yvan-Charvet, L., et al. 2007. Combined deficiency of ABCA1 and ABCG1 promotes foam cell accumulation and accelerates atherosclerosis in mice. J. Clin. Invest. 117:3900-3908.

46. Out, R., et al. 2008. Combined deletion of macrophage ABCA1 and ABCG1 leads to massive lipid accumulation in tissue macrophages and distinct atherosclerosis at relatively low plasma cholesterol levels. Arterioscler. Thromb. Vasc. Biol. 28:258-264.

47. Janssen-Heininger, Y.M., Poynter, M.E., and Baeuerle, P.A. 2000. Recent advances towards understanding redox mechanisms in the activation of nuclear factor kappaB. Free Radic. Biol. Med. 28:1317-1327.

48. de Winther, M.P., Kanters, E., Kraal, G., and Hofker, M.H. 2005. Nuclear factor kappaB signaling in atherogenesis. Arterioscler. Thromb. Vasc. Biol. 25:904-914.

49. Tordjman, K., et al. 2001. PPAR $\alpha$ deficiency reduces insulin resistance and atherosclerosis in apoE-null mice. J. Clin. Invest. 107:1025-1034.

50. Usui, S., Hara, Y., Hosaki, S., and Okazaki, M. 2002. A new on-line dual enzymatic method for simultaneous quantification of cholesterol and triglycerides in lipoproteins by HPLC. J. Lipid Res. 43:805-814.

51. Semenkovich, C.F., Coleman, T., and Daugherty, A. 1998. Effects of heterozygous lipoprotein lipase deficiency on diet-induced atherosclerosis in mice. J. Lipid Res. 39:1141-1151.

52. Reid, P.C., et al. 2004. A novel cholesterol stain reveals early neuronal cholesterol accumulation in the Niemann-Pick type C1 mouse brain. J. Lipid Res. 45:582-591.

53. Jones, C., et al. 2007. Disruption of LDL but not VLDL clearance in autosomal recessive hypercholesterolemia. J. Clin. Invest. 117:165-174.

54. Abdel-Fattah, G., Fernandez, M.L., and McNamara, D.J. 1995. Regulation of guinea pig very low density lipoprotein secretion rates by dietary fat saturation. J. Lipid Res. 36:1188-1198.

55. Westover, E.J., et al. 2006. Rapid transient absorption and biliary secretion of enantiomeric cholesterol in hamsters. J. Lipid Res. 47:2374-2381.

56. Abe, T., et al. 2004. Kupffer cell-derived interleukin 10 is responsible for impaired bacterial clearance in bile duct-ligated mice. Hepatology. 40:414-423.

57. Mak, P.A., et al. 2002. Regulated expression of the apolipoprotein E/C-I/C-IV/C-II gene cluster in murine and human macrophages. A critical role for nuclear liver X receptors alpha and beta. J. Biol. Chem. 277:31900-31908.

58. Dzeletovic, S., Breuer, O., Lund, E., and Diczfalusy, U. 1995. Determination of cholesterol oxidation products in human plasma by isotope dilutionmass spectrometry. Anal. Biochem. 225:73-80. 